Research Article

\title{
Lower-Bound Solution of Foundation-Bearing Capacity under Circular Uniformly Distributed Load
}

\author{
Fang Wei $\mathbb{D},{ }^{1}$ Wang Jiao, ${ }^{1}$ Zhang Wan-dongxing, ${ }^{1}$ and Shi Li-jun ${ }^{2}$ \\ ${ }^{1}$ School of Traffic and Transportation Engineering of Changsha University of Science \& Technology, Changsha 410114, China \\ ${ }^{2}$ Hunan Hongshang Testing Technology Co., Ltd., Changsha 410208, China \\ Correspondence should be addressed to Fang Wei; fangwei5642366@163.com
}

Received 12 May 2020; Revised 13 July 2020; Accepted 21 July 2020; Published 30 July 2020

Academic Editor: Jia-wen Zhou

Copyright (c) 2020 Fang Wei et al. This is an open access article distributed under the Creative Commons Attribution License, which permits unrestricted use, distribution, and reproduction in any medium, provided the original work is properly cited.

The semispatial static allowable stress field was constructed by three-dimensional stress columns, and the analytical lower-bound solution of bearing capacity of Mohr-Coulomb foundation beneath circular uniformly distributed load was put forward for the first time. The influence of the amount of stress columns and soil shear strength parameters on the lower-bound solution of the foundation-bearing capacity is analyzed. The research showed that (1) when the number of stress columns is more than $9(n>4)$ and the friction angle is less than $30^{\circ}$, the relative error between the lower-bound solution of the bearing capacity and exact solution is less than $6.6 \%,(2)$ the suggested analytical solution is applicable for common clayey materials; thus, the application scope of the analytical lower-bound solution is further expanded, and (3) the influence of cohesion on bearing capacity is linear. However, with the increase of the friction angle, the bearing capacity increases faster and faster under all cohesion levels. The correctness and effectiveness of the proposed method were verified by literature comparison.

\section{Introduction}

In the 1950s, Drucker and Prager combined the static field with the kinematical field and put forward the limit analysis method for geotechnical problems, which provided a new tool for solving the limit load of foundations. The limit analysis method includes upper-bound and lower-bound theorems. However, comparing with the kinematically allowable velocity field in the upper-bound method, it is more difficult to establish a static allowable stress field [1]. Fortunately, finite-element technique can provide a powerful tool in solving some lower-bound problems. For instance, $\mathrm{Li}$ and Liu $[2,3]$ established the static allowable field and calculated the ultimate load by means of the finite-element method and linear programming. Singh and Basudhar [4] dealt with the prediction of lower-bound-bearing capacity of smooth (surface) and rough (embedded) strip footings based on finite elements and nonlinear programming. Huang [5] derived the lower-limit solution of the ultimate bearing capacity of a rigid strip footing based on finite element by using second-order cone programming. Furthermore,
Sutcliffe, Yu, and Sloan [6] applied numerical limit analysis to evaluate the bearing capacity of strip footings for a jointed rock mass. Jiang and Sun [7] obtained the numerical solution of the ultimate bearing capacity of the composite pile foundation by using the lower-limit finite-element method. Zhang and Luan [8] deduced the lower-limit solution of the bearing capacity of a strip foundation under the composite loading mode. The solutions of the lower-bound-bearing capacity of reinforced soil-retaining wall, as well as shallow strip foundations in the vicinity of slopes, were successfully investigated $[9,10]$. It could be concluded that research studies on the ultimate bearing capacity in lower-bound analysis concentrated on two-dimensional foundation, and three-dimensional cases were rarely reported [11-14]. However, the spatial effect of circular foundation cannot be ignored. Yang [15] obtained the analytical solution of the lower-limit-bearing capacity of circular foundation for Tresca materials, which is still one step distant from the ordinary foundation. By adopting Hoek-Brown failure criterion, Chakraborty and Kumar [16] evaluated the ultimate bearing capacity of a circular footing, placed over rock 
mass, by using the lower-bound theorem of limit analysis in conjunction with finite elements and nonlinear optimization.

In order to acquire the lower-bound solution of bearing capacity of Mohr-Coulomb foundation beneath circular footing, it is necessary to extend the two-dimensional stress plane to the three-dimensional stress space, which was proved to be feasible for pure cohesive soil [12]. Furthermore, Chen [1] pointed out that since there was no new and physical complexity, it would be essentially possible to build a spatial stress field for soil foundation with $\varphi>0^{\circ}$, and the bearing capacity of threedimensional footing on weightless foundation was sufficiently evaluated.

Based on the existing literature, stress columns were adopted to construct the static allowable stress field which conformed to the principle of the lower-bound theorem. Subsequently, the analytical lower-bound solution of the bearing capacity of Mohr-Coulomb foundation under the circular uniform load was presented. Finally, the results of examples were compared with acknowledged solutions and the reliability of the proposed analytical solution was verified.

\section{Research Background and Lower- Bound Theorem}

The bearing capacity of foundations is one of the three classical problems in soil mechanics. Figure 1(a) displays a typical load-deformation curve of loading tests on surficial footings. The curve contains four sections, which successively represent elastic, elastoplastic, plastic deformation, and strain hardening stage. In order to determine the ultimate bearing capacity $\left(P_{c}\right)$ of the foundation as an elastoplastic material, two methods are usually adopted: one is to investigate the whole evolution process of the foundation, from the elastic deformation state to the plastic limit state, which is based on the theory of plastoelasticity mechanics (Figure 1(b)). Due to the complexity of practical engineering problems, it is usually only suitable for simple working conditions. The second is to ignore the process of elastic deformation, regard the material as a rigid-plastic body, and focus on the behavior of the structure in the plastic limit state, namely, the limit analysis method (Figure 1(c)). It can effectively simplify the analysis process and reflect the most essential content in the plastic deformation, so it is widely used in the engineering field.

If there exists a static allowable stress field throughout the whole object without any yield, which can balance with the load acting on the stress boundary, the object will never fail. When the deformation of the object reaches the limit state, the power of the real surface force in the given velocity field is always greater than (or equal to) the power of the corresponding surface force in the same velocity field of any other static allowable field. The lower-bound theorem indicates that (1) the ideal object can adjust itself to take on the potential external load and (2) among all the loads corresponding to the static allowable stress field, the ultimate load is the largest.
In general, the lower-bound theorem can be cooperated with the upper-bound theorem to define the actual interval of the ultimate load. If the upper limit is equivalent to the lower limit, then the ultimate load is a complete solution.

\section{Spatial Stress Field and Lower- Bound Solution}

According to the theoretical background of the lower-bound method [1, 15], following assumptions are adopted: (1) the foundation bears a circular uniformly distributed load; (2) the foundation is weightless; (3) the foundation is a rigidplastic body, subjecting to the Mohr-Coulomb yield criterion.

3.1. A Single Stress Column. Similar to stress bands adopted in the two-dimensional lower-bound theorem [1], the concept of the three-dimensional stress column is firstly put forward and applied by Yang [15]. It could be utilized to build the spatial static allowable stress field in lower-bound problems. The stress column is defined as an infinitely long "pile" suffering from uniaxial compression. For the simplest case, only one stress column beneath loading area is taken into consideration (Figure 2). Therefore, the lower-bound solution of bearing capacity of the foundation $\left(\sigma_{z}\right)$ could be given by

$$
\sigma_{z}=\frac{2 c \cos \varphi}{1-\sin \varphi},
$$

in which $c$ and $\varphi$ are the cohesion and the friction angle, respectively.

3.2. Five Stress Columns. Subsequently, a static allowable spatial stress field is shown in Figure 3, which is constructed by 5 stress columns. The stress column TO stands beneath the circular uniform load, and the horizontal projection of the cross section of the column totally coincides with the load distribution. The others, $T A, T B, T C$, and $T D$, are evenly distributed on a conical surface with an apex angle of $2 \alpha$, subjecting to $\sin \alpha=\cos \varphi / 2[1,15]$.

The axial compressive stresses of all columns are assumed to be $P$. In order to ensure that the stress state of everywhere in the foundation does not violate the material yield criterion after the superposition of stress fields, a horizontal stress column is added in the foundation with an axial compression of $R=2 c \cos \varphi /(1-\sin \varphi)$. The resultant stress field has omnidirectional symmetry in the horizontal direction. According to stress superposition principle, the resultant stresses along axes $x, y$, and $z$ would be obtained by

$$
\left\{\begin{array}{l}
\sigma_{x}=\sigma_{y}=2 P \sin ^{2} \alpha+R, \\
\sigma_{z}=4 P \cos ^{2} \alpha+P .
\end{array}\right.
$$

Introducing the Mohr-Coulomb yield criterion,

$$
\frac{\sigma_{z}-\sigma_{x}}{2}=\frac{\sigma_{z}+\sigma_{x}}{2} \cdot \sin \varphi+\mathrm{c} \cdot \cos \varphi .
$$

Substituting (2), then 


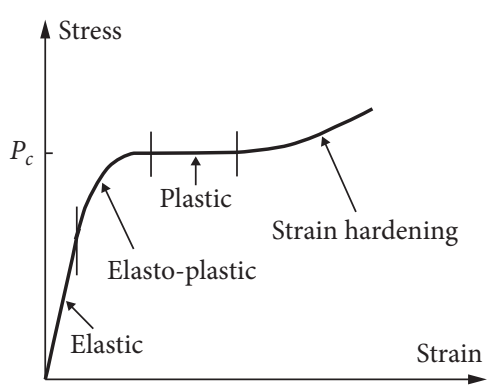

(a)

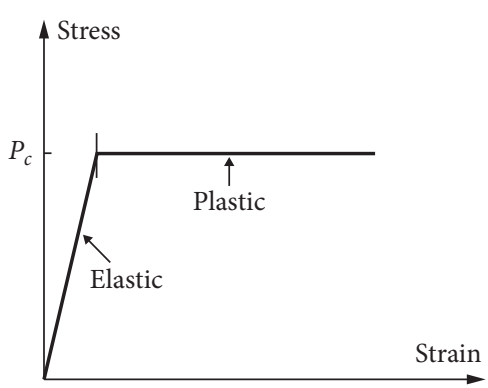

(b)

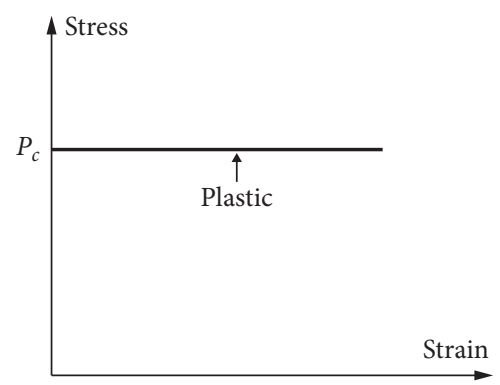

(c)

Figure 1: Deformation curves: (a) common material; (b) ideal elastoplasticity; (c) rigid plasticity.

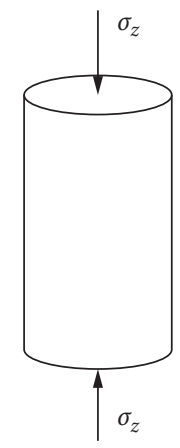

Figure 2: A single stress column.

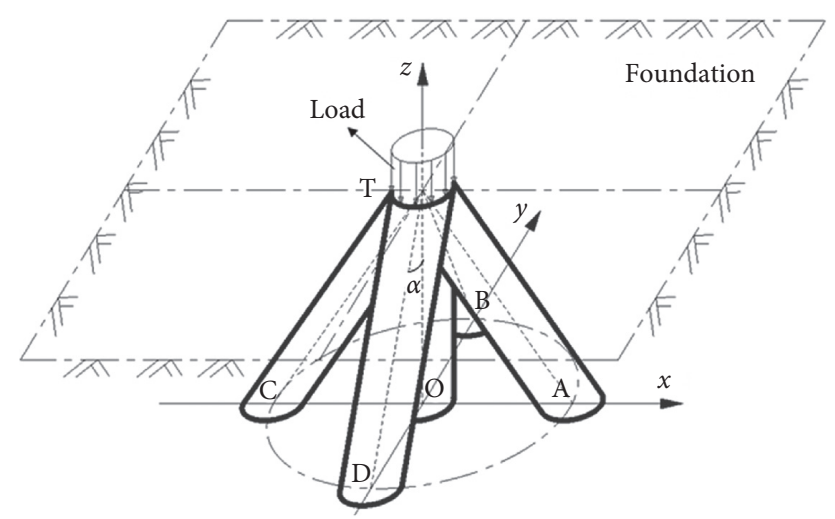

Figure 3: The stress field constructed by 5 stress columns.

$$
P=\frac{(8 c \cdot \cos \varphi / 1-\sin \varphi)}{7+\left(3 \sin \varphi+\cos ^{2} \varphi-10\right) \cdot \sin \varphi} .
$$

As a result, the lower-bound-bearing capacity could be stated as follows:

$$
\sigma_{z}=\left[1+4\left(1-\frac{\cos ^{2} \varphi}{4}\right)\right] P .
$$

3.3. Nine Stress Columns. A more sophisticated static allowable stress field composed of 9 stress columns is shown in Figure 4. Similarly, the stress columns except for TO are

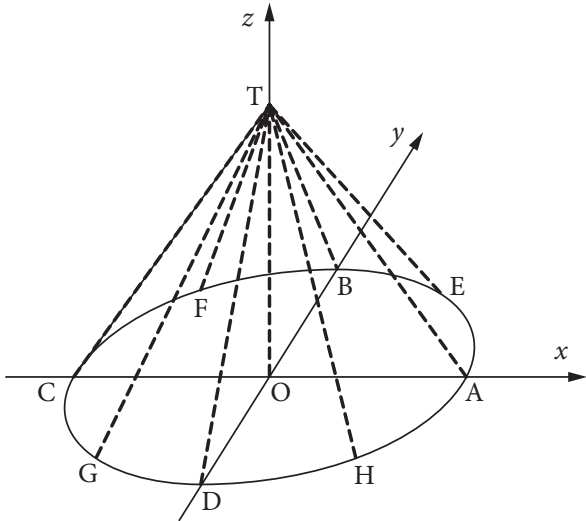

FIgure 4: The stress field constructed by 9 stress columns.

evenly distributed on a conical surface with an apex angle of $2 \alpha$. The axial compressive stresses of all columns are $P$, and a horizontal stress column with an axial compression of $R$ is also supplemented.

The superposed stresses could be given by

$$
\left\{\begin{array}{l}
\sigma_{x}=\sigma_{y}=4 P \sin ^{2} \alpha+R, \\
\sigma_{z}=8 P \cos ^{2} \alpha+P .
\end{array}\right.
$$

According to the Mohr-Coulomb criterion,

$$
P=\frac{(4 c \cdot \cos \varphi / 1-\sin \varphi)}{6+\left(3 \sin \varphi+\cos ^{2} \varphi-9\right) \cdot \sin \varphi} .
$$

Consequently, the lower-bound solution corresponding to 9 stress columns would be

$$
\sigma_{z}=\left[1+8\left(1-\frac{\cos ^{2} \varphi}{4}\right)\right] P .
$$

3.4. Myriad Stress Columns. Above processes could be expanded to stress field constructed by $2 n+1$ ( $n$ is an even number) stress columns, including a vertical column and $2 n$ equiangularly distributed columns on a conical surface with an apex angle of $2 \alpha$. Also, a horizontal stress column with a compression of $R$ is also supplemented. The superposed stresses could be calculated by the following equation: 


$$
\left\{\begin{array}{l}
\sigma_{x}=\sigma_{y}=n P \sin ^{2} \alpha+R \\
\sigma_{z}=2 n P \cos ^{2} \alpha+P .
\end{array}\right.
$$

Considering Mohr-Coulomb failure criterion,

$$
P=\frac{(16 c \cdot \cos \varphi / 1-\sin \varphi)}{5 n+4+\left[3 n \sin \varphi+n \cos ^{2} \varphi-8 n-4\right] \cdot \sin \varphi} .
$$

So, we get

$$
\sigma_{z}=\left[1+2 n\left(1-\frac{\cos ^{2} \varphi}{4}\right)\right] P .
$$

When the number of stress columns increases unlimitedly, as shown in Figure 5, the exact lower-bound solution of bearing capacity could be obtained by

$$
\begin{aligned}
\sigma_{z} & =\lim _{n \rightarrow+\infty}\left[1+2 n\left(1-\frac{\cos ^{2} \varphi}{4}\right)\right] P \\
& =\frac{\left(8 \sin ^{2} \varphi+24\right) \cos \varphi}{(\sin \varphi-1) \cdot\left(7 \sin \varphi-3 \sin ^{2} \varphi+\sin ^{3} \varphi-5\right)} \cdot c .
\end{aligned}
$$

As we know, the slip-line method and the limit equilibrium method can also be employed to solve geotechnical stability problems. The slip-line method tries to derive the plastic equilibrium differential equations and then obtains the corresponding solution by constructing the slip-line network. It is always complicated, and it relies on engineer's experience and judgment to a great extent. On the other hand, a typical failure mode is specified in the limit equilibrium method, and the critical slip surface could be obtained by searching for the minimum safety factor. The deformation or velocity field is not considered in the limit equilibrium method, and the stress distribution beside the slip surface also remains lacking of enough validation. The most significant advantage of limit analysis is that no matter how complex the geometry and load of the structure are, a practical ultimate load can always be obtained conveniently. As presented above, the limit analysis method is competent to obtain the ultimate bearing capacity with such simplicity.

\section{Verification and Evaluation}

\subsection{Literature Comparison}

(1) By extending the $2 \mathrm{D}$ static allowable stress field to 3D environment, $5 c$ was considered to be a lowerbound-bearing capacity of surficial rectangular or square footing with pure cohesive foundation $\left(\varphi=0^{\circ}\right)$. By further improving the stress field, it would also be an eligible solution for all convex footings (such as circular, pentagon, or hexagon base) [1], not far from the solution of this research $(4.8 c)$.

(2) Shield [13] investigated the bearing capacity of circular footing on soil layers with $\varphi=0^{\circ}$, as shown in Figure 6. $B$ and $H$ are the diameter of circular footing and the layer thickness below the base.

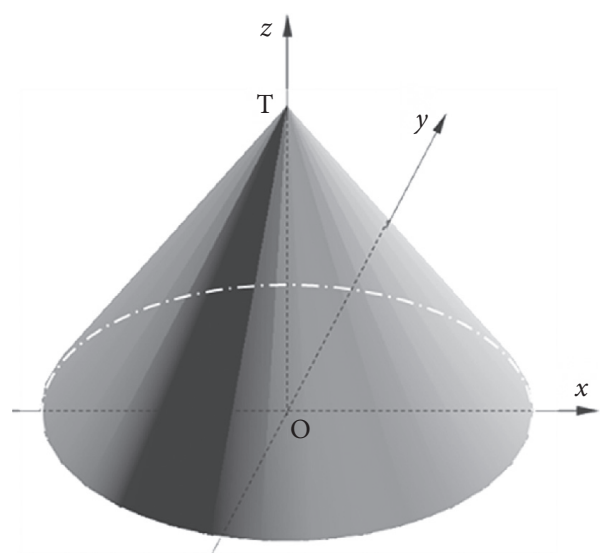

FIgURE 5: The stress field constructed by numerous stress columns.

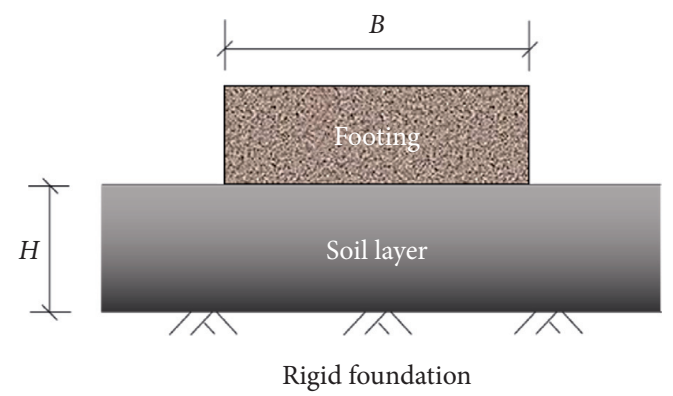

Figure 6: The problem illustration.

As a result, the recommended upper-bound solution could be given by

$$
\sigma_{z}=\left(4.83+\frac{B}{6 H}\right) c .
$$

For semi-infinite homogeneous foundation space, $B$ / $H=0$; then,

$$
\sigma_{z}=4.83 c
$$

Consequently, the upper-bound-bearing capacity of the foundation with circular footing is slightly higher than the suggested lower-bound solution.

(3) Yang [15] performed research on the analytical lower-bound solution of bearing capacity of circular footing upon Tresca foundation, and the comparative results with different stress column numbers are shown in Table 1. It shows no differences between these research studies; thus, the original solution is only the special case of this method at $\varphi=0^{\circ}$. However, Yang's solution is not applicable in ordinary Mohr-Coulomb foundation $\left(\varphi \neq 0^{\circ}\right)$, so the proposed solution in this research would have a larger scope of application.

4.2. The Effect of Stress Column Amount. From (4) and (5), the influence of the number of stress columns on lowerbound-bearing capacity could be easily evaluated. As shown 
TABLE 1: Comparisons of lower-bound solutions with [15] $\left(\sigma_{z} / c\right)$.

\begin{tabular}{lccc}
\hline$N$ & Stress column number $(2 n+1)$ & Ref. [15] & This research \\
\hline 2 & 5 & 4.57 & 4.57 \\
4 & 9 & 4.67 & 4.67 \\
Infinity & Infinity & 4.80 & 4.80 \\
\hline
\end{tabular}

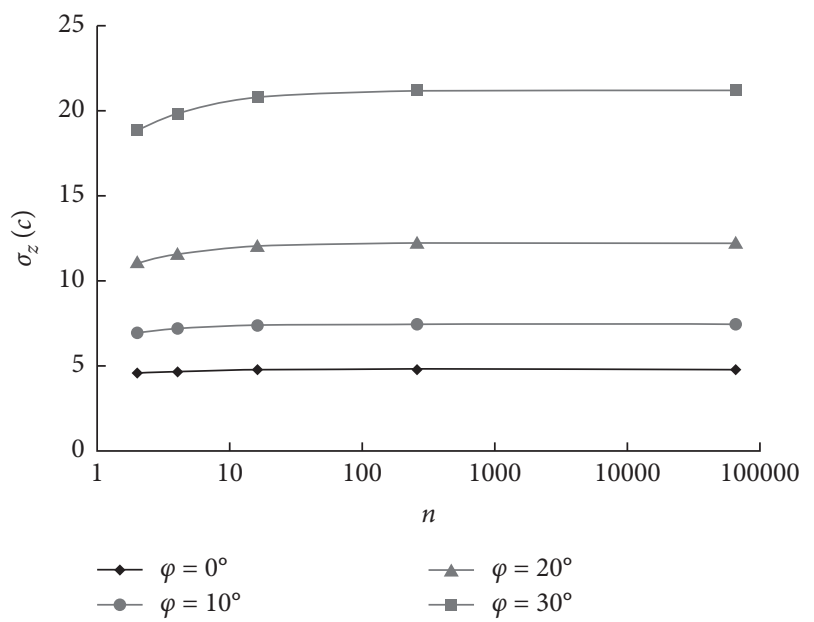

Figure 7: The correlation of bearing capacity and stress column amount.

in Figure 7, with the increase of stress column amount, the lower-bound solution gradually rises and finally converges to the exact solution determined by (12). For cases of $\varphi=0^{\circ}$, $10^{\circ}, 20^{\circ}$, and $30^{\circ}$, the exact solution of $\sigma_{z} / c$ is $4.800,7.466$, 12.209, and 21.192, respectively. Accordingly, Table 2 lists the numerical values and the relative errors of lower-bound solutions regarding variant amount of stress columns. It could be seen that for cases of $n>4$ and $\varphi<30^{\circ}$, the relative errors of lower-bound solution of foundation-bearing capacity would be less than $6.6 \%$. And the relative error will be reduced to less than $2 \%$ while $n>16$ and $\varphi<30^{\circ}$. It means that a better lower-bound solution can be obtained by constructing a more sophisticated static allowable stress field. However, the improvement of lower-bound solution might be inefficient if the stress column amount is large enough.

4.3. The Effect of Shear Strength Parameters. According to (12), it is evident that the cohesion has a linear effect on lower-bound-bearing capacity. The effect of the friction angle is shown in Figure 8, in which the cohesion varies from $10 \mathrm{kPa}$ to $40 \mathrm{kPa}$ and the friction angle locates in the range of $0^{\circ}-30^{\circ}$. The lower-bound-bearing capacity of the foundation with shear strength parameters of $\left(c=10 \mathrm{kPa}, \varphi=0^{\circ}\right)$, $\left(c=40 \mathrm{kPa}, \varphi=0^{\circ}\right), \quad\left(c=10 \mathrm{kPa}, \varphi=30^{\circ}\right)$, and $(c=40 \mathrm{kPa}$, $\varphi=30^{\circ}$ ) would be $48 \mathrm{kPa}, 192 \mathrm{kPa}, 211.92 \mathrm{kPa}$, and $847.69 \mathrm{kPa}$, respectively. It is also indicated that for all cohesion levels, the growth rate of the bearing capacity gradually accelerates as the friction angle increases. The bearing capacity of $\varphi=30^{\circ}$ is about 4.4 times that of $\varphi=0^{\circ}$. As Mohr-Coulomb materials, the bearing capacities of ordinary clayey foundations are much higher than those of
TABLE 2: Relative errors of the lower-bound solution with variant stress columns.

\begin{tabular}{lccc}
\hline$n$ & $\varphi\left(^{\circ}\right)$ & $\sigma_{z}(c)$ & Error $(\%)$ \\
\hline $2^{1}$ & 0 & 4.571 & -4.76 \\
$2^{2}$ & 0 & 4.667 & -2.78 \\
$2^{4}$ & 0 & 4.762 & -0.79 \\
$2^{8}$ & 0 & 4.798 & -0.05 \\
$2^{16}$ & 0 & 4.800 & 0.00 \\
$2^{1}$ & 10 & 6.958 & -6.80 \\
$2^{2}$ & 10 & 7.167 & -4.00 \\
$2^{4}$ & 10 & 7.380 & -1.15 \\
$2^{8}$ & 10 & 7.460 & -0.08 \\
$2^{16}$ & 10 & 7.466 & 0.00 \\
$2^{1}$ & 20 & 11.113 & -8.98 \\
$2^{2}$ & 20 & 11.560 & -5.32 \\
$2^{4}$ & 20 & 12.021 & -1.54 \\
$2^{8}$ & 20 & 12.197 & -0.10 \\
$2^{16}$ & 20 & 12.209 & 0.00 \\
$2^{1}$ & 30 & 18.845 & -11.08 \\
$2^{2}$ & 30 & 19.795 & -6.59 \\
$2^{4}$ & 30 & 20.785 & -1.92 \\
$2^{8}$ & 30 & 21.165 & -0.13 \\
$2^{16}$ & 30 & 21.192 & 0.00 \\
\hline
\end{tabular}

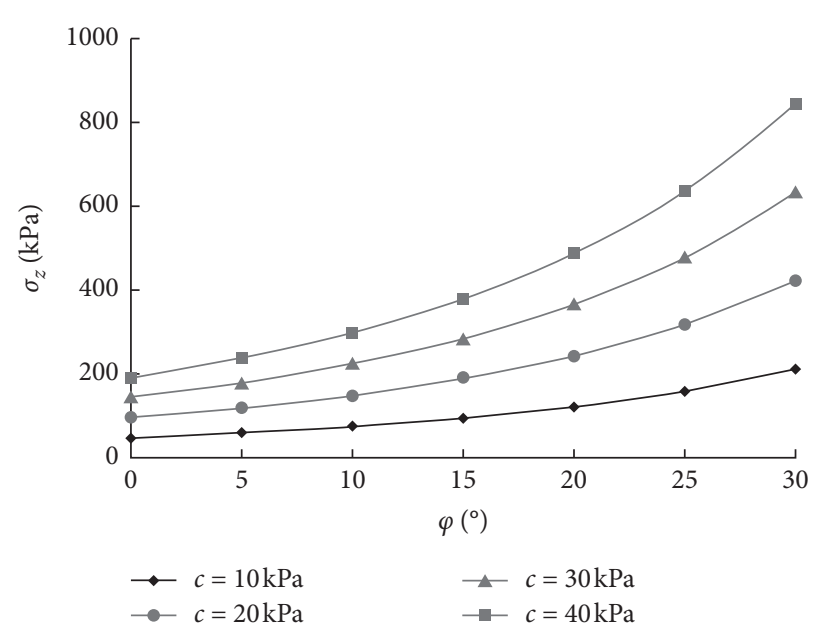

FIgURE 8: The correlation of bearing capacity and friction angle.

Tresca material or pure cohesive soil. It can also partly explain why the base built in clay is more reliable than that in silt or sand.

\section{Conclusions}

Three-dimensional stress columns were adopted to build the half-spacial stress field for foundation beneath circular uniform load. The analytical lower-bound solution of bearing capacity of Mohr-Coulomb foundation, which greatly expanded the application scope of the original solution, was presented for the first time. Both effects of the stress column amount and shear strength parameters were evaluated, and the validity of the proposed solution was verified by the previous literature.

This study further enriches the relevant research results of the limit analysis method in the field of foundation- 
bearing capacity. Furthermore, the circular uniformly distributed load in this paper can be extended to any centrosymmetric distribution shape so long as the resultant force passes through the centroid vertically.

\section{Data Availability}

A part of the raw data cannot be shared at this time as the data also form part of an ongoing study.

\section{Conflicts of Interest}

The author declares that there are no conflicts of interest regarding the publication of this paper.

\section{Acknowledgments}

This work was funded by the Natural Science Foundation, China, grant number: 51408059 .

\section{References}

[1] W. F. Chen, Limit Analysis and Soil Plasticity, Elsevier Science, Amsterdam, 1975.

[2] L. Li and B. C. Liu, "Lower bound limit analysis on bearing capacity of slope and its reliability," Chinese Journal of Rock Mechanics and Engineering, vol. 20, no. 4, pp. 508-513, 2001.

[3] L. Li and B. C. Liu, "Ultimate bearing capacity on slope by lower bound analysis method," China Railway Science, vol. 22, no. 1, pp. 79-83, 2001.

[4] D. N. Singh and P. K. Basudhar, "Optimal lower bound bearing capacity of strip footings," Soils and Foundations, vol. 33, no. 4, pp. 18-25, 1993.

[5] Q. W. Huang, M. S. Huang, and G. H. Wang, "Calculation of bearing capacity of strip footings using lower bound limit method," Chinese Journal of Geotechnical Engineering, vol. 29, no. 4, pp. 572-579, 2007.

[6] D. J. Sutcliffe, H. S. Yu, and S. W. Sloan, "Lower bound solutions for bearing capacity of jointed rock," Computers and Geotechnics, vol. 31, no. 1, pp. 23-36, 2004.

[7] G. Sun, J. Sun, and X. D. Wang, "Finite element lower bound limit solutions for ultimate bearing capacity of subsoil under raft of composite piled foundations," Chinese Journal of Geotechnical Engineering, vol. 33, no. 1, pp. 128-134, 2011.

[8] Q. Y. Zhang, M. T. Luan, and S. F. Zhao, "Lower bound limit analysis of bearing capacity of strip footing due to combined loading," Journal of China University of Mining \& Technology, vol. 37, no. 3, pp. 364-368, 2008.

[9] D. N. Singh and P. K. Basudhar, "Determination of the optimal lower-bound-bearing capacity of reinforced soilretaining walls by using finite elements and non-linear programming," Geotextiles and Geomembranes, vol. 12, no. 7, pp. 665-686, 1993.

[10] F. K. Ahmad, I. Ardavan, and J. C. Reza, "Seismic bearing capacity of shallow strip foundations in the vicinity of slopes using the lower bound finite element method," Soils and Foundations, vol. 59, no. 6, pp. 1891-1905, 2019.

[11] J. X. Wang, Y. F. Wu, and Z. Li, "Lower bound theory of 3-D plastic limit analysis and its application," Rock and Soil Mechanics, vol. 25, no. 10, pp. 1627-1631, 2004.

[12] R. T. Shield, "The plastic indentation of a layer by a flat punch," Quarterly of Applied Mathematics, vol. 13, no. 1, pp. 27-46, 1955.
[13] R. T. Shield, "On Coulomb's law of failure in soils," Journal of the Mechanics \& Physics of Solids, vol. 4, no. 1, pp. 10-16, 1955.

[14] H. J. Yang, Z. J. Shen, and J. H. Wang, "3D lower bound bearing capacity of smooth rectangular surface footings," Mechanics Research Communications, vol. 30, no. 5, pp. 481-492, 2003.

[15] X. L. Yang and L. Li, "Discussion about lower-bound analytical solution of circular foundation bearing capacity using limit analysis method," Journal of the China Railway Society, vol. 23, no. 6, pp. 77-80, 2001.

[16] M. Chakraborty and J. Kumar, "Bearing capacity of circular footings over rock mass by using axisymmetric quasi lower bound finite element limit analysis," Computers and Geotechnics, vol. 70, pp. 138-149, 2015. 